Claremont Colleges

Scholarship@ Claremont

CGU Faculty Publications and Research

CGU Faculty Scholarship

$8-1-2008$

\title{
A Mismatch with Dual Process Models of Addiction Rooted in Psychology
}

Reinout W.Wiers

Remco Havermans

Roland Deutsch

Alan W. Stacy

Claremont Graduate University

\section{Recommended Citation}

Wiers, Reinout W., Remco Havermans, Roland Deutsch, and Alan W. Stacy. "A Mismatch with Dual Process Models of Addiction Rooted in Psychology." Behavioral and Brain Sciences 31.4 (2008): 460. doi: 10.1017/S0140525X08004962

This Article is brought to you for free and open access by the CGU Faculty Scholarship at Scholarship @ Claremont. It has been accepted for inclusion in CGU Faculty Publications and Research by an authorized administrator of Scholarship @ Claremont. For more information, please contact scholarship@cuc.claremont.edu. 


\section{A mismatch with dual process models of addiction rooted in psychology}

\section{doi:10.1017/S0140525X08004962}

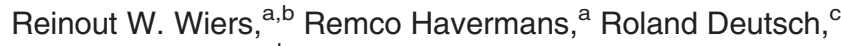 and Alan W. Stacy ${ }^{d}$ \\ ${ }^{a}$ Department of Clinical Psychological Science, Maastricht University, 6200 MD Maastricht, The Netherlands; ${ }^{\mathrm{b}}$ Behavioural Science Institute, Radboud University Nijmegen, 6500 HC Nijmegen, The Netherlands; ${ }^{\circ}$ Department of Social Psychology, Würzburg University, 97070 Würzburg, Germany; Institute for Health Promotion and Disease Prevention Research, University of Southern California, Los Angeles, CA 91803. \\ r.wiers@psychology.unimaas.nl \\ r.havermans@psychology.unimaas.nl \\ deutsch@psychologie.uni-wuerzburg.de \\ astacy@usc.edu} of fit with recent data and models in psychological studies of addiction. In these dual process models, relatively automatic appetitive processes are distinguished from explicit goal-directed expectancies and motives, whereas these are all grouped together in the planning system in the Redish et al. model. Implications are discussed.

We appreciate the attempt in the target article by Redish et al. to provide an integrative framework for addiction from a multiple systems view, and we find many of the suggestions regarding addictive behaviors thought provoking. Our main concern is related to the lack of fit of the theoretical framework with recent data and models from psychological science.

Redish et al. distinguish between two broad processes that jointly explain addictions: an explicit and slow planning system, relying on stimulus/response-outcome (S/R-O) associations, and an implicit and fast habit system relying on stimulus-action/response (S-A/R) associations (Table 3 of the target article). In many recent psychological theories of addiction, a distinction is also made between two broad systems that superficially resemble the proposed systems (e.g., Deutsch \& Strack 2006; Evans \& Coventry 2006; Stacy \& Wiers 2006; Wiers \& Stacy 2006a; 2006b; Wiers et al. 2007). These models follow general dual process models in psychology in which the most characteristic difference between the systems concerns the representational format, not the contents of the associations (e.g., Strack \& Deutsch 2004). In this model, the reflective system uses the representations in the impulsive system and can perform logical operations on these representations, such as negation or placing the contents in a different time (e.g., the future). Deutsch et al. (2006) have demonstrated the consequence of this difference in representational format. When an association is learned and later participants are told that in fact the association was not true, participants correct this as becomes evident from their explicit expectancies, but when their automatic associations are assessed, they still show the original association. A study by Krank and Swift (1994) shows that this can have serious real-life consequences: adolescents who were told that alcohol does not make you sexy (a prevalent alcohol expectancy in adolescents; Goldman et al. 1999), showed stronger automatic associations between alcohol and sex a week later. This effect is opposite to what would be predicted if this association was only governed by a propositional planning system (cf. Gawronski et al. 2008).

Relatedly, Redish et al. do not acknowledge a range of automatic associations that are conceptual (multi-modal) in nature, which do not necessarily involve $\mathrm{S}-\mathrm{A} / \mathrm{R}$ associations. These associative processes can be dissociated from explicit memory and operations of the planning systems. Examples include associations processed during semantic priming (e.g., Hutchison 2003; Weingardt et al. 1996), implicit conceptual memory (e.g., Levy et al. 2004), or construct activation tasks (e.g., Arndt et al. 2002). The automatic activation of a variety of different classes of associations (beyond S-A/R) can spontaneously bias processing and judgments in ways that do not appear to involve planning, as revealed in social psychological research (e.g., Bargh \& Morsella 2008). Hence, our general point here is that there are many more associative processes that predict behavior than the $\mathrm{S}-\mathrm{A} / \mathrm{R}$ associations of the habit system and that these can be dissociated from explicit memory processes in the planning system.

When we turn to psychological addiction research, recent studies have found that relatively automatic processes such as an attentional bias for a substance, automatic memory associations, and action tendencies to approach alcohol are relatively independent from explicit processes such as motives and expectancies (see Wiers et al. 2007 for a review). Expectancies and substance associations typically show low correlations and predict unique variance in substance use (e.g., Houben \& Wiers 2006; Stacy 1997; Wiers et al. 2002). In recent studies, the relative predictive power of automatic substance associations and explicit expectancies to explain substance use was assessed in adolescents who differed in working memory (WM) capacity. For smoking (Grenard et al., in press) and alcohol use (Thush et al. 2008), substance use was better predicted by automatic associations in participants with relatively poor WM capacity. Interestingly, Thush et al. (2008) found the opposite pattern for explicit expectancies, which predicted alcohol use better in participants with high WM capacity. Hence, some individuals' substance use appears to be more driven by their automatic associations, whereas others (with equally strong automatic substance associations but with a stronger WM capacity on top) appear to be more "rational" substance users. In summary, the distinction between relatively automatic or implicit associations and explicit expectancies has been fruitful in psychological research on addiction (see Wiers \& Stacy 2006a; 2006b; Wiers et al. 2005; 2007). Although Redish et al. also differentiate between two main systems (planning and habit), many of the processes distinguished in psychological research appear to be inaccurately grouped together and subsumed in their planning system.

A third issue concerns the role of conscious motivation in drug seeking. Redish et al. state that overvaluation of expected drug outcomes leads to craving and that this overvaluation in the planning system might be the result of incentive salience attribution, citing Robinson and Berridge (1993; 2003). These authors, however, differentiate between "wanting," the neural process of incentive salience attribution, and subjective craving, which can, but does not necessarily, result from the unconscious "wanting" process. This distinction may explain, for example, that smokers, after a Pavlovian conditioning procedure, show strong approach tendencies to smoking stimuli, particularly in the presence of cues predicting smoking opportunity, without these cues eliciting increased subjective craving (Thewissen et al. 2007). In line with this distinction, a recent meta-analysis found low correlations between subjective craving and an attentional bias for alcohol (Field et al., in preparation). Redish et al. attribute devaluation and need-dependent evaluations exclusively to the planning system. However, recent studies suggest that automatic evaluations can be need-dependent (e.g., Seibt et al. 2007).

In summary, we believe that there is evidence that relatively automatic appetitive processes in addiction should not be categorized together with subjective craving and explicit expectancies in the planning system. This does not imply that they are part of the habit system either. Perhaps these relatively automatic processes are an intermediate step between explicit processes in the planning system characteristic of drug use initiation and the reward independent associations characteristic of the habit system in late phases of addiction (cf. Everitt \& Robbins 2005). 